\title{
Juan de Arona, Romántico del Perú
}

\author{
Caballero de la Inteligencia
}

L título de este ensayo exige una explicación inicial. Creemos en el romanticismo de Juan de Arona, como en una categoría primordial que antecede a toda otra consideración de escuela literaria o de época. Precisamente, por esta previa y absoluta condición, es su figura tan esencial en el Perí. Símbolo o síntesis de un romanticismo integral frente a nuestra realidad. Sus actitudes ante la vida, ante sí propio y ante la sociedad, descubren su dolor de humanidad un poco desengañada ante los hechos que lo rodean cercanamente, pero de alucinado fervor cuando sueña con un mundo de más amplios horizontes.

Fué por ello, Juan de Arona, caballero de la Inteligencia, generoso dador de sus riquezas espirituales y paladín sin tacha de toda empresa ideal. Dueño de una magnífica cultura humanista, se erige a la manera de un apóstol civil, trabajando en una cruzada que — sabía demasiado- no iba a terminar nunca. De su empresa, y de su noble entusiasmo por la tierra, dejó abundantes ejecutorias. $\mathrm{Y}$ porque tuvo una superioridad tan natural fué, también, odiado por la medianía, que no alcanzó a comprender su independencia sin claudicaciones.

Juan de Arona, Juan sin tierra

A fines de mayo de 1839 nacia, de noble hogar, Pedro Paz Soldán y Unánue. Hijo de Pedro Paz Soldán, recibía de su padre el legado de una austera tradición intelectual. Nieto de Hipólito 
Unánue por línea materna, convergían en él las fuerzas de una indiscutible aristocracia de pensamiento, sumadas a la muy pura prestancia natural de las dos sangres.

Pudo el joven heredero ufanarse de tan afortunada situación en la vida, dejándose llevar sin esfuerzo por las comodidades de un hogar brillante, y cultivando con alegre fervor los blasones de una tradición familiar. Sin embargo, el joven escritor descleña estas frágiles posibilidades de su existencia y, atrabiliario pero tenaz en su actitud humana, renuncia gallardamente a las ventajas que el destino le ofrecía. No es negación ni rechazo su renuncia, más bien es deseo íntimo de exaltar, con nuevas fuerzas, el prestigio de su apellido, ya no asidero o escalón, sino pretexto de lucha y ufanía.

Así es como surge este Juan de Arona de todos sus libros, que sintetiza en su leyenda una fórmula de renunciamiento y de afirmación. Renunciamiento de privilegios de sangre que él no quiere aprovechar; afirmación del sentimiento de la naturaleza, como paisaje y como razón humana, que normaria durante toda su vida los movimientos de su voluntad. Nace en este instante, en las letras peruanas, este personaje de nuestra costa, Juan de Arona, que lleva en sí el anonimato de todos los juanes del Perú, pero el íntimo sabor a terruño, entre reseco y húmedo, de nuestro litoral. A varias leguas de Lima, isla de verdor entre oleajes de arena, surgen las tierras de la vieja hacienda. Como en un apartamiento horaciano, Paz Soldán discurre por la campiña entoldada, hermanándose con las plantas y deletreando, en sus tonos multicolores, una sabia doctrina del Perú. Pronto, a la experiencia del campo de Cañete y a la experiencia libresca del Convictorio de San Carlos, unirá una educación cambiante y multiforme de viajero impenitente.

El padre intuye en los movimientos de este muchacho inquieto la necesidad de abrir, ante sus ojos, más amplias y aireadas perspectivas. Por eso autoriza el primer viaje del niño por la costa peruana hasta Iquique, cuando el futuro poeta sólo contaba doce años de edad. El "sendero innumerable" se abre ante su curiosidad rampante. Confronta costa y mar, tasa el tiempo que se consume a medida que avanza el barco dibujando, inútilmente, un fútil camino. En cambio, las huellas en su espíritu son más profundas. Una gula de viajar, que es amor de conocer, repite en su alma el eco de las palabras de Gracián: "Condición tiene de linda la varia naturaleza, pues quiere ser atendida y celebrada. Imprimió por ello en 
nuestros ánimos una viva propensión a escudriñar sus puntuales efectos..." Una honda y densa necesidad de conocer todo lo cambiante y perennemente inédito de la naturaleza, lo impulsa a salir del Perú, y en el año de 1859 partía, ya en los albores de una juventud vigilante, hacia el viejo continente.

Tal deseo de expresarse y de comunicar sus impresiones invadió al adolescente, que las páginas de Memorias de un viajero peruano fueron, más que trabajo literario, necesaria, sabia y espontánea terapéutica de su espíritu. Ancha alegría invade su aventura. Repite la impresión de dos años antes, cuando hizo un viaje a Valparaíso y Santiago. Sin embargo, esta visita a Europa cobra nuevos brillos en su imaginación. Salido del Callao el 12 de abril, llega a Southampton el 19 de mayo. Conoce a Londres y corre a deslumbrarse en París. Con rapidez turística abandona la Ciudad Latina, para dirigirse a tierras españolas. Estamos a mediados de junio: primero Bilbao, en seguida Burgos, luego Valladolid y, por último, la capital madrileña. Todo el mes de agosto lo dedicó a conocerla. Abundantes y agudas notas de criollo observador se deslizan en su diario. Se duele un poco del tipo de curiosidad que despierta el americano: "En España -cuenta- Americano es simplemente sinónimo de Creso, y antes que simpatía, inspiramos curiosidad..." Continúa sus andanzas por la península y se reintegra a París a fines de 1859.

Casi dos años permanece en la capital francesa dedicado, con religioso entusiasmo, a sus estudios humanistas. Apenas alguna escapada nocturna matizaba esta doctrina de museos y bibliotecas. Entre diciembre de 1859 y septiembre de 1861, asiste a la Sorbona, al Colegio de Francia, a estudiar Derecho, y sigue lecciones de Historia Natural en el Jardín de las Plantas. Día a día revisa los clásicos y crece, robustece y amplía su sentimiento de antigüedad. Conocedor del Griego y del Latín, comparte las emociones estéticas de sus lecturas literarias con la aventura científica de sus hallazgos filológicos. $\mathrm{Y}$ esa profunda entraña campesina que le viene desde sus años mozos, se estructura y adorna con los conocimientos sistemáticos con que se enriquece infatigablemente. $\mathrm{Y}$ en esta lejanía de su tierra natal, es donde prospera y crece más intensa su devoción peruana. No por la patria chica mezquina y limitada, sino por la gran patria que, con valentía y conocimiento, ansía reformar. $\mathrm{Su}$ estada en Europa perfecciona, también, su innata facilidad para 
los idiomas. E1 inglés, el francés, el italiano, el alemán, el griego moderno y aun el chino, fueron familiares para Juan de Arona, y ésta es otra de las cualidades de su talento múltiple y privilegiado.

En septiembre de 1861 parte para Alemania. Viajero sin descanso, pronto se encontrará en Praga y, casi en seguida, en Viena. Luego pasa a la capital de Hungría, la belleza de cuyas mujeres le arranca un encendido elogio. Las tierras italianas reclaman su atención: Venecia, Padua, Mantua con la augusta sombra de Virgilio. Luego de pasar por Génova, Pisa y Florencia, culmina su peregrinaje en Roma. A continuación, delectaciones morosas en Pompeya y Herculano; viaje a Malta y, días después, las costas africanas. Cuando Juan de Arona recorre a Alejandría, el Cairo, Beirut y Suez, se da cuenta que los días han pasado rápidamente, y el mes de abril de 1862 marca su mano en el tiempo. Visita, todavía, a Chipre y Rodas y, a fines del mes, entra en Constantinopla. ¿Un viaje bizantino? Quién sabe si un poco de esto. Pero el poeta adquiere un tono universal y sus ademanes son, cada día, más ágiles. Gasta los últimos meses del año en retornar a los paisajes predilectos de Italia y Francia, y en 1863 llega al Perú. Contaba, a la sazón, menos de veinticinco años; pero qué recia y qué íntegra lucía su cultura, puesta desde ese instante al servicio de un Perú que zahería en la misma medida de su cariño esencial.

De regreso a la patria, Arona se dirige hacia la hacienda que había servido para bautizarlo perdurablemente. Son años de trabajo, de meditación y de romance. La fuerte y dulce aventura del amor llega a su existencia, y se enamora de la que lo acompañará como esposa. E1 año de 1867 se casa con Cipriana Vallerriestra, y su cariño crece como una flor roja y extraña que llena su corazón y estremece su vida. Con los años, los hijos le traen nuevas bellezas. También los años le traerán una pérdida irremediable, cuando en 1876 muere su esposa, dejando en su vida un vacío que no podrá llenar jamás.

En tanto, alterna sus actividades de publicista con sus labores en el Ministerio de Relaciones Exteriores, a cuyo cuerpo pertenece desde 1872. Encargado de Negocios Interino en Chile, tiene que afrontar los momentos trascendentales anteriores a la Guerra del Pacífico. Concluída ésta, continuará sus brillantes gestiones en la Argentina y el Brasil, reintegrándose al Perú poco antes de la muerte de su esposa. Su actividad era no sólo fecunda sino, tam- 
bién, múltiple. A Ruinas, ensayos poéticos publicados en París en 1863, habían seguido, entre otros libros, la traducción de las Geórgicas de Virgilio (1867), simultánea a la aparición de sus célebres Cuadros y episodios peruanos y a la primera de sus comedias, El intrigante castigado. Los años que corren entre el 69 y el 83, corresponden a diversas producciones de género lírico o dramático. E1 año de 1884 significa la aparición de su Diccionario de peruanismos, largamente gestado, y la de su agudo libro satírico: Vivir es defenderse. Dificultades de Basilio a través de la vida limeña y Diario de un Pensador, donde anotaba audaces pensamientos sobre nuestra realidad, que le granjearon frecuentes ataques.

En los últimos años de su vida, alterna la publicación de su diario satírico El Chispazo y la edición de Sonetos y chispazos (1885), con la orientación de su pluma hacia temas serios. Ya es miembro correspondiente de la Real Academia Española de la Lengua, y compone su "Canto a Lesseps" y "La venganza de la muerte", con un poema elegíaco dedicado a la compañera desaparecida. El año de Páginas diplomáticas, y antes de su muerte, termina La Linea de Chorrillos, pintoresco comentario a nuestros incipientes balnearios.

Muere el 5 de enero de 1895, luego de haber cumplido generosamente el programa de su vida. Había gozado mucho, sufrido hondo, y luchado sin descanso. Con soberbìa y sin claudicaciones dejó, sobre el perfil del tiempo, la figura del ciudadano a la manera antigua, íntegro y fuerte, fértil en la alegría y varonilmente rudo en la apreciación de los defectos que ambicionaba extirpar en esta patria de anchas costas.

\section{El sentido de la tierra}

Fué desde muy joven, en sus años de Europa, cuando Juan de Arona sintió revivir, con fulgor triunfante, las matizadas visiones de su tierra natal. Varios años transcurridos durante su niñez, bajo el encanto rural de los valles de la costa peruana, habían marcado un transparente sendero para su inspiración. Fué, entre los románticos, por edad un poco posterior a ellos, quien con quintaesenciada sinceridad sintió el encanto de su tierra. Descubrir en nuestra costa la belleza de sus poblados y sus campiñas; buscarla, infatigablemente, en tierras donde la neblina, la garúa o la arena 
ponen, con frecuencia, una pausa de desaliento, requiere fina y acongojada sensibilidad. Sin el triunfante cromatismo de los paisajes cordilleranos, nuestro litoral se desenvuelve en una teoría de medios tonos. Pintura de silencios, de grandes vacíos sobre el fondo de un cielo muchas veces gris y pocas rutilante. Pequeña y suave geografía de las lomas, arrebatándole al mar algo de su dominio sobre las arenas fijas o viajeras. Clima tibio, donde la humedad enseñorea los minutos, y el espacio se adensa en cercanía marina. Aquí los colores se acallan y hay como un olvido de Dios, como lo recuerda el propio poeta en uno de sus cáusticos sonetos:

Diz que Dios, al pasar la costa nuestra

- "Quita allá" - dijo- y la pasó de un tranco.

$Y$ es por esta razón, página en blanco

de natura en la obra tan maestra.

¿Qué importa que, jamás, nube siniestra

borde de fuego de su cielo el flanco,

si la arena, el desierto y el barranco

del olvido de Dios dan triste muestra?

Africa es ésta, sin camello y palma, ni hay montes, ríos, árboles, ni lagos grandes azas, para elevar el alma.

Pobreza, desnudez, contornos vagos. $\mathrm{Y}$ un bello clima, $\mathrm{y}$ una dulce calma que dan la muerte entre embriaguez $y$ halagos. 1

Concebía, Juan de Arona, la misión del artista con verdadera austeridad: descubrir la belleza; agotar el contenido del paisaje en todo resquicio o huella portadora de un mensaje divino. Sin esfuerzo, con suavidad ufana, el poeta ve desenvolverse la vida del litoral. Casi con acuciosidad de botánico, examina y hace el inventario lírico de nuestra flora. Las plantas indígenas servirán de gala para decorar muchos de sus versos; instantáneas, algunos de ellos; otros, discretos recuentos de riuestra riqueza floral.

Riva Agüero, Jiménez Borja, y aun García Calderón, descubren esta virtud descriptiva de Arona, que el primero reconoce de estirpe latina. "El traductor de las Geórgicas - dice Riva Agüero- ha empleado en estos cuadros y episodios, procedimientos descriptivos esencialmente virgilianos, en ocasiones muy elegantes, que contrastan 
de curiosa manera con su realismo de pintura, con su genuino tono criollo y con la multitud de provincialismos que esmaltan el lenguaje." 2 Y verdaderamente, si alguna objeción pudiera hacerse al matiz de su inspiración, seria la de haber puesto un barniz clásico en su poesía que, importando una nota de recatada frialdad, detiene un poco la emoción, que debió ser más espontánea y fluyente.

Ya en Ruinas, libro publicado en 1863, Arona había adelantado fragmentos de lo que serían, cuatro años después, los Cuadros y episodios peruanos. Desde su retiro de París, recuerda el paisaje de Pachacamac junto al mar. Su visión es medida llena de pudor retórico pero, también, de una grave ternura que le sirve de fondo:

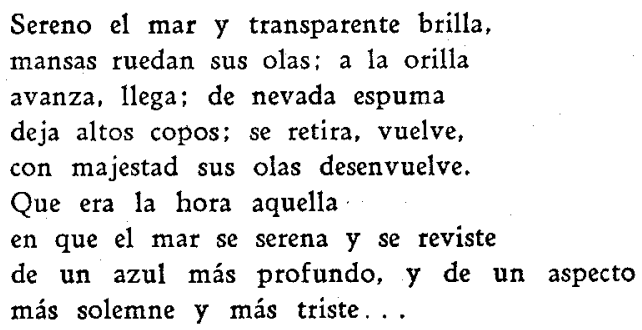

$\mathrm{Y}$ al describir una de las madrugadas entre rosa y plomo, en su rústica estancia de la hacienda, da cauce a su criolla ironía, envuelta en una tónica virgiliana que sorprende con la suavidad de sus colores :

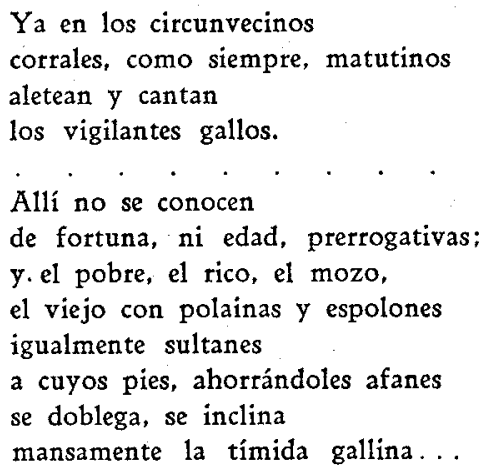

Insensiblemente esa falta de perspectiva que se aprecia en el colorido local, ha de irse perdiendo. El poeta se reintegra a la pa- 
tria y a la tierra. Siente el hervor de la gleba fecunda, y el chasquido de las ramas y de las hojas. Fuertes y tenues son los aromas de las plantas indígenas. Esa nueva fragancia y los medios tonos del crepúsculo costeño, ingresarán en su poesía sin esfuerzo, como una nueva curiosidad o una nueva maravilla. Días anteriores a su matrimonio, que el poeta los gasta en paseos largos y meditados por los caprichosos senderos de la campiña. Entonces reclama un lenguaje, no extranjero sino peruano, para su inspiración:

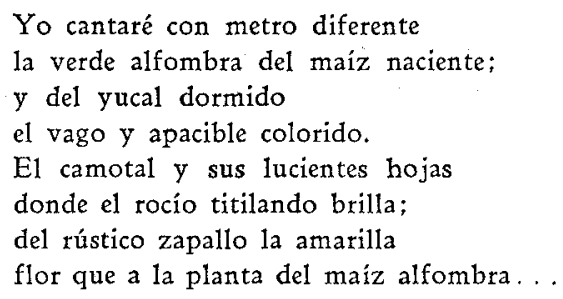

Frecuentemente la descripción es alada y grácil:

De los parajes solitarios gala

jquién del atomo iguala

la vaguedad del natural donaire

cuando en la cima del collado erguido

con el ramaje horizontal tendido

nadar parece en la mitad del aire!. . .

A veces, piensa que nuestro paisaje costeño no deja de ser gris, y lo confiesa, en breves pinceladas:

Con el polvo que lo viste

aquí el árbol más lozano

arrastra el follaje cano,

y el campo más fresco es triste

como la faz de un anciano...

Luego, completando su libro, intenta el paisaje animado. Cuadros costumbristas de nuestra costa, llenos de sabor campestre, donde hasta el alimento lugareño tiene una risueña glosa:

Viva la chicha que ensancha

los ánimos apocados, 


$$
\begin{aligned}
& \text { y iviva la chomba ancha! } \\
& \text { y iviva también la cancha } \\
& \text { que es pan comido a puñados! }
\end{aligned}
$$

$\mathrm{Y}$ cuando la costa amanece llena de sol, el poeta se llena de un vibrante optimismo matinal:

Amable, tierna y risueña
raya en el oriente el alba.
Risueña porque promete
una de aquellas mañanas
(no raras en nuestro invierno)
en que están las nubes altas,
y del campo los colores
con más viveza resaltan...

Aquí podríamos hacer un templado paréntesis en los Cuadros y episodios peruanos, para recordar otra pintura del poeta, cuando la costa no descansa, sino en movimiento por milagro de la naturaleza, fuga en complicadas teorías. Para quien haya tenido que ver, alguna vez, con las abstrusas leyes de la Preceptiva Literaria, no ha de extrañar el interés que Juan de Arona puso al componer "Los Médanos", poema pentasílabo alegórico-descriptivo.

No se escapa al más tranquilo y confiado lector, que Juan de Arona obedeció, tanto al versátil capricho geográfico de los médanos, como a ese noble y santísimo deseo de vencer una dificultad de versificación. Hay tan alada métrica en las estrofillas, ya que no estrofas de su poema, que la imaginación cambia, rápidamente, de lugar como los arenosos montículos, en fuga alada sobre la costa peruana, a veces con flexibilidades femeninas $y$, otras, con torvos, peligrosos y cegadores espejismos.

Quién sabe si Juan de Arona creyó ver en los médanos retrato sin caricatura de mucho de este espíritu que se ha dado en llamar criollo. Perspicaz y agudo como médano de la costa norte o sur, tiene también confiadas superficies llenas de armonía, pero en un movimiento perenne que le impide enraizarse en lo profundo. Demasiada agilidad de superficie, sin adentrarse todo lo necesario en la entraña misma de la tierra. Médano y no médula, como mímica transitoria y cambiante, pero llena de simpatía.

Juan de Arona veía los médanos como seres mitológicos, silfos benignos que desarrollan una teoría cambiante. El imprescindible 
sentido humorístico de Arona, le hace tejer con sus ritmos a la manera de un burlesque, que hoy hubiéramos incorporado a cualquier bella sinfonía de color proyectada por Walt Disney:

$$
\begin{aligned}
& \text { Silfos y Nomos } \\
& \text { viva el donaire } \\
& \text { de los que somos } \\
& \text { hijos del aire. }
\end{aligned}
$$

Médanos enemigos de los viajeros, contribuyen a extraviarlos en los desiertos costeños:

$$
\begin{aligned}
& \text { Ay del que pisa } \\
& \text { nuestro recinto } \\
& \text { do se improvisa } \\
& \text { el laberinto... }
\end{aligned}
$$

$\mathrm{Y}$ al final del poema, describe su anatomía en palabras líricas de gran sugerencia:

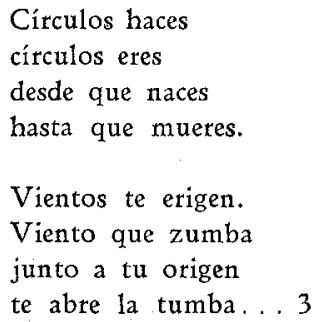

No pudo el poeta dotar de mejores pies sus médanos. Deslizándose sobre un, casi patinador, verso pentasílabo, los médanos recorren la atención del lector alegremente, frente a la grácil transparencia del cristal del cielo, reflejando un mar de arena, a ratos movedizo y a ratos tormentoso.

\section{El poeta humanista}

Nunca olvidó, Juan de Arona, los bellos días de su permanencia en la Sorbona. La amplia cultura, llena de grave seguridad, que aureolaba sus escritos, provenía, en último y definitivo término, de 
esa privilegiada condición de su cultura humanista. Sus amplios estudios clásicos dejaron en su alma un profundo respeto por los frisos majestuosos de una antigüedad que, para él, no significaba lejanía, sino cercana eternidad. No por ejercicio, sino por gozo estético, lejos de toda vanidad o diletantismo fueron sus traducciones.

La figura del poeta mantuano, lo seduce singularmente. Virgilio, mago de la sugestión y señor de sobria elegancia, surge ante su vista como modelo de muy elevada y caballeresca inspiración. Y a él dedicó lo mejor, no de sus ocios, sino de las más selectas horas de trabajo artístico. Recorriendo con paso lento y cauto las Geórgicas o la Eneida, gustando sus mieles afinadas, transcurrían muchas horas insensiblemente. De vez en vez, alguna travesura dejaba su picante huella, pero noble, sin dura trascendencia, ni rencor retórico.

En el prólogo a su libro de Poesía latina, publicado en Lima el año de 1883, platica con Menéndez y Pelayo acerca de sus dudas filológicas, con acentos de reconcentrado humanista, y luego reune diversos fragmentos de sus placeres clásicos: traducciones de Lucrecio, Virgilio y Ovidio y pasajes llenos de vivacidad de Plauto.

Sin embargo, Poesía latina tenía un antecedente en las Geórgicas de Virgilio, publicada, esta obra, por nuestro poeta el año de 1867. Los fragmentos que la integraban habian aparecido en $E l$ Nacional, diario limeño, en el mes de septiembre de 1866. Otro poeta romántico, José Arnaldo Márquez, rival literario de Arona, declaró que las traducciones eran muy malas, y para decirlo compuso cuatro sonetos sucesivos, que vieron la luz en su semanario El Cosmorama. 4 El primero de ellos lleva por título "La Expiación de Virgilio" y, a la letra, es como sigue:

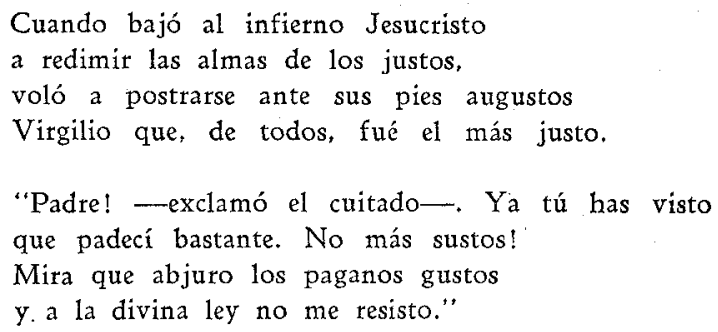


Volvió Cristo los ojos paternales, $y$ con dulce y severa voz le dijo:

"La piedad de mi padre te perdona

Y el cielo debe abrirte sus umbrales.

Pero antes de eso, has de ser mártir, hijo."

-Y tradujo a Virgilio Juan de Arona.

El soneto está hecho con evidente gracia, así como los que le siguieron. Pero Juan de Arona no se quedó callado y, al replicarle, le aconsejó a Márquez una serie de cosas y afirmó que comía alfalfa y que rebuznaba. Todavía más; lo bautizó, haciendo un juego de palabras con su apellido, como José Asnaldo Marcado. Al enterarse de todo esto, Menéndez y Pelayo se escandalizaba de lo despreciables que son las costumbres literarias en el Perú.

Desde luego que Juan de Arona no traduce los cuatro libros de las Geórgicas, sino exclusivamente el primero, donde, cuando lo desea, se eleva serenamente sobre el cielo itálico, y su voz es segura y amplia en su timbre:

\author{
...Mirarás deslizarse las estrellas \\ por la celeste alfombra, \\ dejando largas, luminosas huellas \\ en la mitad de la nocturina sombra. \\ La leve paja y las caducas frondas \\ el aire turban y la luz se ciega, \\ y tal cual pluma sobrenada y juega \\ por cima de las ondas... 5
}

\title{
Inconformidad y poesía
}

En Juan de Arona, como en Ricardo Palma, concurrieron fuerzas disímiles en su inspiración. Al mismo tiempo románticos y satíricos logran, por razón de su destino, una línea de humorismo que los eleva y, también, los ata fuertemente a la teoría de nuestra pertanidad. Maestro en el cultivo del epigrama, Juan de Arona supo todas las cortantes sutilidades de la palabra. No conoce la dócil discreción del silencio conformista, ni la broma ausente surgida a media voz. No son hijos naturales los de su ingenio, sino vástagos de pujante y declarada paternidad. Su masculinidad de vigor incon- 
tenible surge en La Saeta o en El Chispazo, certeros apellidos periodísticos de los semanarios que editó. Fulge en el aire la hoja de su ingenio, $y$ la herida es honda pero, también, saludable. A veces cultiva el epigrama sin finalidad cáustica, como lujo de idioma. En Ruinas o en Sonetos y chispazos, en La Saeta o en El Chispazo, ataca la complicidad de todos los silencios y, risueño pero seguro, predica las candentes verdades.

Los temas más diversos desfilan por la inspiración de Arona. Ya surge el soneto intencionado, para describir a cierta amorosa señora:

Doña Paconia Palomar y Castro
que en Enero cumplió setenta y siete,
a pesar de su adorno y su casquete
es la señora tal, un avucastro.
Su cuello no da envidia al alabastro,
el catarro a toda hora la acomete
y así vieja, y con cara de machete
tiene más presunción que un poetastro.

Cierto anciano con frac, guantes $y$ broche

la visita, y afirman que la adora

y que, también, le ha regalado un coche.

Yo no sé si el buen viejo la enamora, pero él entra en su casa por la noche y sale de ella al despuntar la aurora. . 6

Magnífico en el cultivo del soneto, rival en maestría con Salaverry, a quien supera en agudeza, le da el tono criollo que esplende en aquella "Invitación a toros":

Hijos del Imperial y Pueblo Nuevo;

hijos de Chilca, Pacarán y Mala,

de las corridas acudid al cebo

con que el pueblo vejano hoy os regala.

El decrépito viejo y el mancebo,

el hacendado y el que avienta pala,

el que se alumbra en el galpón con sebo,

$y$ el que usa Kerosina y vive en sala. 
Sin hacer distinción de jerarquías todos acudan, pues se invita a todos a disfrutar de tan cabales días.

No se usará altivez, ni malos modos que en tan dulce fusión no se consiente más señor, ni más Dios que el aguardiente. . . 7

Hay discusiones sobre quién tuvo más audacia en sus epigramas: si José Joaquín de Larriva o Juan de Arona. Nos lo podrían decir José Díez Canseco o Raúl Porras. Yo sólo podría atestiguar sobre su pasión por expresarse con demasiada franqueza. En su ironía reconcentrada, hay abundantes muestras de una malicia exenta de ese amargor que se le ha querido atribuir. En cierta ocasión define a un candidato a parlamentario en forma muy elocuente:

\author{
Inmóvil como una roca \\ yace aquí, don Juan Petate. \\ Nunca dijo un disparate \\ porque... nunca abrió la boca.
}

En otra oportunidad ensaya una definición sobre las habilidades estéticas de algunas mujeres:

- Artista insigne es Jacinta.

-Oh, pinta que es un primor.

-Muy bien pinta, muy bien pinta...

-Pero se pinta mejor...

¿Y qué decir de Juan de Arona, cuando con ironía pungente bebe en un pasaje de Petronio (El Satiricón, CXI-CXII), para escribir ese delicioso pequeño libro titulado La Matrona de Efeso? Allí, con verso audaz, aunque siempre alto, cuenta la popular historia de esta dama castísima que, a la muerte de su esposo, no lo quiere abandonar ni aun en la tumba, y como dice el poeta:

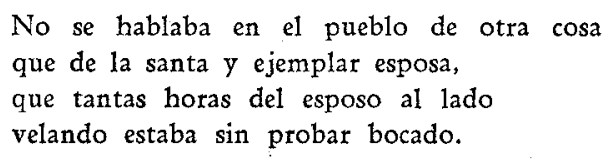


y que, sin embargo, sucumbe por muy disculpables debilidades de la naturaleza ante el primer soldado que llega a la tumba a ofrecerle compartir su ración, caballeroso enemigo de las hambres atrasadas de las matronas.

Hay en estas páginas un sano escepticismo, una sonrisa volteriana que tan frecuentemente vivía en los labios de Juan de Arona, un poco para escandalizar a las gentes medidas, otro poco por ese espíritu liberal de aguijón incansable, del cual nunca se pudo liberar.

"La España Teutónica" y "La Pinzonada", aparecidas en 1867 (aunque los versos firmados en Cañete, 1864), corresponden al tipo de la sátira política. El mismo Juan de Arona se encarga de recordárnoslo en una nota en que dice que ambas composiciones se escribieron con motivo de la presencia de la Escuadra Española en las islas Chincha. La primera fué publicada en El Comercio bajo el anagrama de Jenaro Vanda; y la segunda en El Tiempo, el 8 de octubre de 1864, bajo el seudónimo de Bagruiel de los marros. El tono de ambos poemas es sarcástico y agraz, concluyendo el primero con esta invectiva contra España:

$\mathrm{Y}$ al robarse otra vez nuestro tesoro sólo prueban bien claro y con cinismo, que si el conquistador vino por oro el reconquistador viene a lo mismo...

E1 segundo poema hace la parodia del famoso almirante Luis Pinzón, que fracasada su empresa:

Viendo que aquí la trampa se lo lleva,
haciendo su postrera pinzonada
"miró al soslayo, fuése y no hubo nada..."

También "Los Rotonautas", publicado en 1880, pertenece a este tipo de poesía. Constituía una sátira dirigida a Chile en momentos en que, a consecuencias de la Guerra del Pacífico, nuestras relaciones no eran excesivamente cálidas. Para dar movimiento al poema, Juan de Arona alterna los versos decasílabos con los exasílabos, obteniendo una agradable armonía para el oído. Las alusiones directas al problema del momento circunscriben el papel poético de esta composición hacia una finalidad política. 
Tanto como los problemas internacionales, interesaron a Juan de Arona los vaivenes de la política interna, sobre los cuales hace consideraciones palpitantes de ironía:

\author{
Doña Patria y Don Gobierno, \\ es decir, hombre y mujer, \\ marchan juntos actualmente \\ como todo el mundo ve. \\ Pero hay una diferencia, \\ $y$ esta diferencia es \\ que el uno marcha a caballo \\ y la otra camina a pie. .
}

Cada vez es más claro su lenguaje. Tendríamos, simplemente, que trasladarnos a uno de los mejores espejos de costumbrismo en nuestra época republicana. Nos referimos a Vivir es defenderse, Dificultades de Basilio al través de la vida limeña y Diario de un Pensador. Singularmente Basilio, personaje central, es digno sucesor republicano del niño Goyito de Felipe Pardo, pero con los más opuestos caracteres. Lo podríamos llamar el anti-goyito, producto alquitarado de la vida republicana, que se asusta con los temblores inmemoriales de Lima, pero que, también, es frenético orador político. La Patria atraviesa, por el sutil hilo de la ironía de Arona, sin detenerse. El poeta dice su más franca sátira, a la manera clásica, en "El Diario de un Pensador". Su palabra es vigorosa y lapidaria contra toda lacra: "E1 Perú - dice- es un vasto desierto de gente y una gran población de palabras". En otras ocasiones, se aparta del comentario local, para decir amargas filosofías del cotidiano vivir: "Para prosperar en este mundo - escribe - hay que buscar no amigos sino cómplices".

El año de 1891 vió la luz El Chispazo. Arona advertía, en una anotación, que era la segunda época de La Saeta. Pero este periódico, publicado en 1869, había tenido muy pocos números de vida. No obstante se declaraba "vibrante, hiriente, volante, ligerísimo y punzante" y ante todo - añadía - "nacional". En buena cuenta, hubiera podido uno pensar que esas cualidades que Arona atribuía a su semanario eran el resultado de la introspección de su propia conciencia. 
El Chispazo, dentro de su constante y nunca domeñada rebeldía, tuvo una larga existencia, que se prolongó durante los años de 1891, 92 y 93. Era como una isla artillada de ntestra costa, poderosamente dotada para herir a todos los barcos corsarios de la peruanidad. Desde esta cátedra popular y un poco hosca, Juan de Arona dictaba constantes lecciones de gallardía y soberbia. Una experiencia de veintidós años transcurridos entre sus dos periódicos, le hizo declarar afirmativamente que estaba resuelto a ocuparse de política. Consecuente a su propósito, dijo muchas cosas que desagradaron a las gentes; pero Juan de Arona no cambió de camino.

Sería difícil decir aquí todo lo que, en sus páginas, tiene un picante sabor criollo o una encendida admonición. Simplemente recordaremos uno de sus sonetos y una letrilla que revelan el ingenio rampante de todas las épocas de su vida:

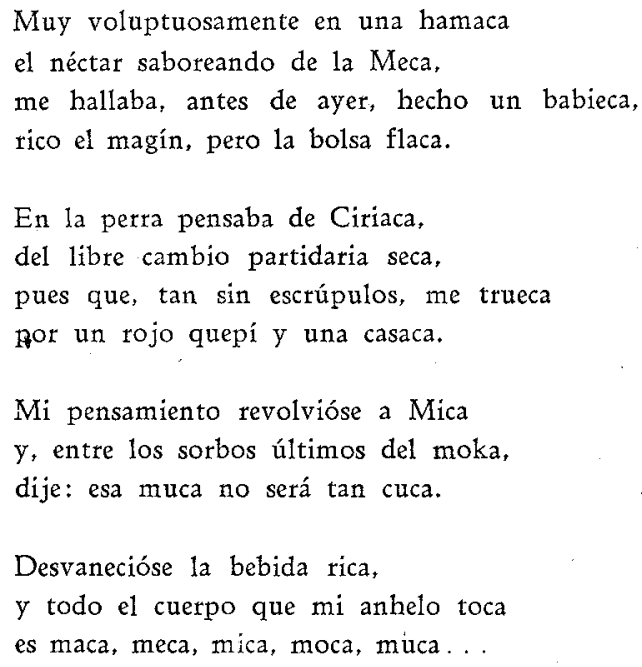

Y esta indirecta a un bibliófilo:

Yace aquí Fray Mamerto de Hinestroza, que fué el porro más porro de los porros. jamás de estudios serios supo cosa, y murió el infeliz de una espantosa indigestión de títulos y forros... 
Fino pintor, Arona, en sus cuadros peruanos, se revela incomparable caricaturista en su obra satírica. Y no sabemos qué aspecto de su labor fué más fecundo: si cuando copia con cariño nuestros paisajes, o cuando - con cariño también - sueña con un Perú redimido.

\section{Interludio teatral}

Poco se acostumbra recordar la obra dramática de Juan de Arona. Los que lo conocemos como afortunado traductor de Plauto y dueño de muchas de sus prerrogativas, nos admiramos, aún más, de que su actividad literaria no se hubiera orientado con mayor intensidad en este campo. De todos modos, nuestro genial satírico dejó algunas huellas de su ingenio en breves comedias, impregnadas de una gracia francesa que comunica leve flexibilidad a sus creaciones.

Quisiéramos, aquí, recordar sus tres juguetes cómicos, cuyos títulos hacen pensar en el risueño bagaje de su contenido. Publicado El intransigente castigado en 1867, le sigue Más, menos, ni más ni menos cuatro años después, y Pasada, pesada en posada el año de 1883. Las fechas de las respectivas ediciones no son índice estricto de la época de su composición, pues el propio Juan de Arona se encarga de advertirnos en la portada de la primera de sus comedias, que fué escrita a los dieciocho años, y lo avisa, no por hacerse pasar por niño prodigio, sino para evitar que se le juzgue por tan imberbe producción.

Fué el suyo el tipo de la comedia ligera francesa, cuyo argumento, bola de nieve, al decir de Bergson, al rodar va creciendo insensiblemente en sus equivocos, hasta que, de pronto, se pulveriza totalmente. De las tres comedias de Arona, dos se desarrollan en el Perú y la tercera en España, pero con protagonistas americanos, excesivamente criollos, que se enamoran de la criada de la posada y le prometen maravillas. Esta Pilarica, casada con un gallego, tan bonita como práctica, les saca las monedas de oro, pero no se casa: con ninguno de sus tres pretendientes. El viejo don Ernesto se emociona mucho en el elogio de la bella y tartamudea:

Digo... lo que digo, digo,

digo que es mucha mujer... 
pero ella no les da confianza, porque su abuelito le había contado una vez que los hombres son malos y cuando se les da la mano se van hasta el codo.

Más, menos, ni más ni menos fué estrenada con éxito en Lima el 19 de enero de 1871 y está dedicada al Presidente de la República, coronel José Balta. Una casa de pensión, y una joven soltera con su padre, sirven de marco para el acalorado entusiasmo de dos jóvenes pretendientes. Uno es extremadamente delgado y se llama Canuto; el otro, grandemente obeso, y lleva el nombre de Pancho. Esta Aurora, que no ha de amanecer para ellos, termina desdeñándolos, a uno por defecto y a otro por exceso:

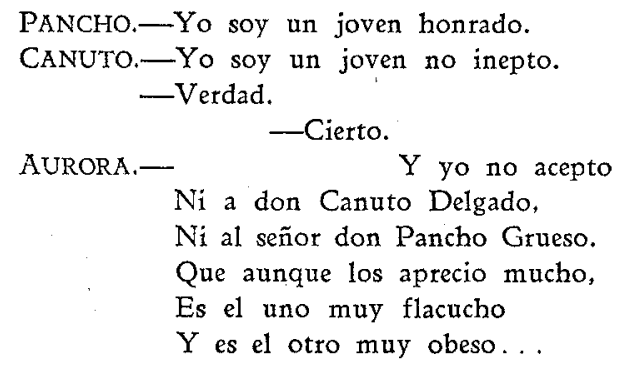

y termina casándose con su primo, uno de esos insoportables primos de familia, que destruyen nuestras más justas esperanzas amorosas. Así vivió y realizó, Juan de Arona, un teatro leve e intrascendente en comedias llenas de un ágil ingenio limeño y de una elegante malicia. Pero cuando es demandado para la realización de un tema patriótico, pone su entusiasmo sin reticencias al servicio de una límpida inspiración. Las sombras inmortales de la Patria, alegoría dramática, fué compuesta por Juan de Arona respondiendo a una amable solicitud. Debía estrenarse el 28 de julio de 1890, y para lograr su forma buscó aliento en El pabellón peruano de Luis B. Cisneros, que hondamente lo había impresionado en los años de su juventud. Toma elementos del poeta laureado, y los incorpora a su alegoría, explicando este proceso en el prólogo a su pequeño libro.

En el templo de la Gloria se encuentran los mausoleos de Bolívar y San Martín. La Gloria baja de su altar y ordena a los héroes que salgan de sus tumbas. La primera pregunta de Bolívar es: 
La Gloria contesta que no los hay. Luego ingresa la $\mathrm{Paz}$, y en la bella escena siguiente se rinde tributo de admiración a Miguel Grau. Recordando la historia, se comprende el deseo del actor Luis Roncoroni, de pedir una obra distinta a la de Cisneros. Las condiciones del Perú habían variado y la Guerra del Pacífico había añadido nuevos laureles a nuestro panteón. Así, dentro de lo breve de su producción escénica, Juan de Arona no olvidó una afirmación de emocionada peruanidad.

\section{El lenguaje peruano}

Como expresión de las hondas y permanentes vinculaciones de Juan de Arona con la patria, su Diccionario de peruanismos, obra largamente gestada y recompuesta en los diferentes pasajes de su vida, ve la luz ya en los últimos años, cuando en 1884 se anima a darla a la imprenta. En el prólogo cuenta cómo en Londres, por el año de 1861, concibió la idea de una especie de galería de novedades filológicas que constituiría un vocabulario de peruanismos. Su permanencia en la Sorbona, y sus constantes estudios de las lenguas clásicas, le permitieron establecer con agudeza las misteriosas relaciones que existen en los orígenes de las palabras. Estaba persuadido de las secretas afinidades entre el cuerpo de las lenguas y el alma de los pueblos que presiden la génesis y el desarrollo de los vocablos indígenas. Juan de Arona fué, con Palma, pioneer de nuestras investigaciones lingüísticas y valientes defensores -ambosde nuestra contribución léxica al acervo común de la Lengua Castellana. Vitalidad del idioma nativo frente a las trabas del conquistador que, encastillado en un purismo anacrónico y absurdo, pretendía ignorar la marcha del mundo. Juan de Arona pensaba que, en esta imposición de los vocablos, en esta pugna por ocupar un puesto en la vida de expresión, había que descubrir una pujante ley biológica. Aquí cabrían las palabras de Alfonso Reyes, en un diálogo de sutil gramaticidad: "En la lengua vulgar descubro los movimientos del lenguaje vịvo, y en cada dislate de los palurdos persigo lo que podrá ser nuestra lengua culta del porvenir." 8 Con este mismo criterio, Juan de Arona, a través de veinte años de su vida, se dedica a observar las diferentes acciones y reacciones del lenguaje 
peruano, y forma riquísimo conjunto de notas que le permitirán estructurar su Diccionario de peruanismos.

En cuanto a su concepto del peruanismo, el propio Paz Soldán se encarga de comunicárnoslo: "Entiendo por término peruano o peruanismo, no sólo aquellas voces que realmente lo son, por ser derivadas del quichua, o corrompidas del español o inventadas por los criollos con el auxilio de la Lengua Castellana, sino también aquellas que, aunque nuy castizas, aluden a objetos o costumbres tan generales entre nosotros y tan comunes en España, que nos las podemos apropiar y llamarlas peruanismos como si no estuvieran en el Diccionario de la Academia Española. A esta clase pertenecen los términos que el lector hallará passim en este libro, de quebrada, sanices, retamas, aromos, que tienen para nosotros una significación y una importancia que no pueden tener en España, donde, o no son tan abundantes como aquí, o se hallan oscurecidos por otros objetos de mayor apariencia". Es decir, Juan de Arona, frente al problema lingüístico, adopta una posición mucho más liberal que la que adoptaría la Academia Española frente a la incorporación de los peruanismos en su diccionario: amplitud de criterio de un lado, y anquilosamiento dogmático por el otro.

No se limita, Paz Soldán, a establecer una ordenación alfabética, de sus papeletas, para constituir su diccionario, sino que lo precede de una extensa sección titulada de "observaciones generales". En ella ausculta y expone varios de nuestros fenómenos lingüísticos, partiendo de lo puramente gramatical para proyectarse a formas generosamente literarias.

Ya en el planteamiento objetivo de los vocablos Arona adopta un alegre tono literario, que hace a su libro agradable de leer, no obstante su finalidad cientifica. No se limita a la aclaración del vocablo, ni a su rectificación, sino, con levedad literaria, engarza el comentario irónico e ilustra la afirmación con apuntes poéticos, en muchas ocasiones debidos a su propia pluma. Uno se sorprende de semejante inmodestia de ejemplificar con sus mismas producciones. Pero una lectura minuciosa permite apreciar que, si Juan de Arona utiliza sus versos para explicar algunos pasajes de su diccionario, lo realiza impulsado por el carácter de su inspiración: pocos poetas contemporáneos suyos habian tenido tan peruana preocupación de emplear términos locales en sus versos, contrastando con el cons- 
tante interés que él, siempre, mantuvo de acentuar esta expresión de su nacionalismo.

De todo ello se desprende que el Diccionario de pernanismos, no obstante ser una obra de contenido científico, no pierde en ningún momento su alegre sabor criollo. Tal ocurre, también, con otro libro de Juan de Arona que, aunque nada tiene que ver con cuestiones filológicas, quiero mencionarlo en este momento. Me refiero a $L a$ Linea de Chorrillos, de ambiente turístico, pues trata desde un triple punto histórico-filológico-geográfico la ventura y aventura de los tres balnearios aledaños a Lima, Chorrillos, Barranco y Miraflores. La Linea de Chorrillos la publicó Juan de Arona en su vejez, por el año de 1894. Esta descripción de los balnearios es amena, y lo es sin desdeñar sus rasgos eruditos. El cáustico genio de Arona lo impulsa a la anécdota incontenible e incontenida, a la alusión política que se eleva en el surtidor de la pila de Miraflores, o entre los cascos del paciente pollino poblano que, con sus pisadas, contribuye a formar el camino carretero que el Gobierno inaugurará después, solemne y trascendental.

La meditación de su realidad de escritor, al tratar de Juan de Arona, nos hace volver a un pensamiento fundamental en lo que respecta a la actitud vital de nuestros románticos. En el Perú, el romanticismo adoptó una fisonomía inconfundible. Los poetas fueron, al mismo tiempo, ingenuamente apasionados y escépticamente irónicos. Posición contradictoria pero cierta, que asumieron en la vida y en la literatura y que se dibuja en nuestra historia literaria con un poco de afirmación y otro poco de inseguridad dubitativa.

\section{El Perí, razón suprema}

En cálidas líneas, Oscar Barrenechea y Raygada ha recorrido la actividad diplomática de Pedro Paz Soldán y Unánue. Aquí tenemos que olvidarnos, por un breve instante, de su seudónimo de Juan de Arona, que solamente abandonó para todo aquello que pudiera estar relacionado con su labor diplomática. Orientado en la carrera descle años jóvenes, asciende hasta la Jefatura de la Sección Diplomática. El año de 1876 parte a Chile, para poner la contribución de su cultura al servicio de los altos intereses de la patria. No como poeta, sino como hombre de amplia y generosa cultura humanista, 
va con el ademán preciso de su certeza humana. $\mathrm{Y}$ fueron años no fáciles los que el azar puso en su camino. Su sagacidad y la intuición del porvenir del Perú, le permitieron conocer la gravedad de los hechos: "Como peruano y como ministro aconsejo precaverse...", decía dirigiéndose a nuestra Cancillería. Terminados los años dolorosos, continúa su gestión diplomática en Argentina y Brasil. De regreso al Perú, quiso hacer perdurar en un libro básico la historia de nuestras relaciones internacionales desde los primeros tiempos de la República. Dificultades de orden material fueron reduciendo, cada vez más, el radio de amplitud de su esperanza. Entonces se conforma con publicar sus Páginas diplomáticas del Perú en Lima, el año de 1891, como un adelanto a lo que hubiera ambicionado ver en una obra más vasta.

Aunque no corresponde al tipo de nuestro ensayo ahondar en este aspecto de la vida de Pedro Paz Soldán, quisiéramos destacarlo en cuanto contribuye a la composición de su perfil moral. Tuvo, con excepcionales condiciones y con un fervor lleno de nobleza, el sentido de lo patriótico. Su patriotismo fué esencial, básico y estructurado. Caló, hasta lo más profundo, el sentido de nuestra nacionalidad, la que zahirió cuando fué necesario, y exaltó en sus aspectos más intensos. Así pudo realizar, con sabor y armonía clásica, su realidad de habitante de esta tierra, no con pasividad acomodaticia, sino con virilidad actuante, trabajando por forjar un Estado, como organismo vivo y saludable, siempre en el puesto de lucha ante toda llamada, ya fuera del éxito o de la desdicha.

Y su interés por los problemas sociales del Perú se confirma en otra de sus obras dada a luz en esos días. La inmigración en el Perú no es la información pedestre, ni el elogio áulico. Constituye una de esas admoniciones que Juan de Arona, con su tradicional franqueza, emprende con fines regeneradores. Románticamente aspiraba a ser oído. Grave optimismo el de Paz Soldán, su obra ha quedado como valor de biblioteca y de consulta.

\section{Universalidad y peruanidad}

Si se nos preguntara: de toda esta arbitraria actividad de creación seguida por el poeta, ¿cuál es la contribución sustantiva del hombre a los destinos del país?, tendríamos que pensar que en esta 
cambiante y fugaz angustia de su vida se nos revela, una vez más, el sentido agónico y romántico del poeta. Tal dispersión de su labor hubiera podido ser fatal, para una contextura espiritual más débil que la de Juan de Arona. Pero de su misma y aparente debilidad, es de donde extrae la fuerza de su mensaje. Sin traicionar su propia nacionalidad, los años de Europa dejaron en su espíritu una riquísima lección de cultura, que avaloró los quilates de su crítica. Bebió en las fuentes clásicas, y en los viejos cauces de la cultura europea, todos los elementos que le abrían una más amplia perspectiva vital. Poseyó la intuición y la convicción de que, partiendo de lo universal, la emoción de lo propio crece más cercana y evidente. $Y$ a la mànera de un héroe laico o de un ciudadano antiguo, se sacrificó en la vibrante y siempre aguda prédica que soñaba por la construcción de una patria mejor.

\section{Luis Fabio Xammar, Lima, Perú.}

\section{NOTAS}

1 Juan de Arona, Sonetos y chispazos. Lima, 1885.

2 José de là Riva Agüero, Carácter de la literatura del Perú independiente. Lima, 1905.

3 Juan de Arona, "Los Médanos". Lima, 1869.

4 El Cosmorama, semanatio satírico. Lima, 1867.

5 Juan de Arona, Las Geórgicas de Virgilio. Traducción en verso castellano del libro primero.. Lima, 1867.

6 Juan de Arona, Ruinas, ensayos poéticos. París, 1863.

7 Juan de Arona, Sonetos y chispazos. Lima, 1885.

8 Alfonso Reyes, El cazador. Madrid, 1921. 